\title{
A Comparison of the Performances of Different Mesoporous Titanias in Dye-Sensitized Solar Cells
}

\author{
Alessandro Latini, ${ }^{1}$ Riccardo Panetta, ${ }^{1}$ Carmen Cavallo, ${ }^{1}$ \\ Daniele Gozzi, ${ }^{1}$ and Simone Quaranta ${ }^{2}$ \\ ${ }^{1}$ Dipartimento di Chimica, Università degli Studi di Roma La Sapienza, Piazzale Aldo Moro 5, 00185 Roma, Italy \\ ${ }^{2}$ Faculty of Science, University of Ontario Institute of Technology, 2000 Simcoe Street North, Oshawa, ON, Canada L1H 7L7 \\ Correspondence should be addressed to Alessandro Latini; alessandro.latini@uniromal.it
}

Received 13 January 2015; Revised 8 May 2015; Accepted 10 May 2015

Academic Editor: William W. Yu

Copyright (C) 2015 Alessandro Latini et al. This is an open access article distributed under the Creative Commons Attribution License, which permits unrestricted use, distribution, and reproduction in any medium, provided the original work is properly cited.

The present work aims at optimizing titanium dioxide morphology for dye-sensitized solar cells applications. Five different anatase phase mesoporous titanias were prepared and tested as photoanodes in dye-sensitized solar cells. The materials were prepared by using a template approach. Two materials were synthesized by using monodisperse silica nanospheres and the other three using two different organic templating agents (Pluronic P123 and Brij 58). A complete characterization of the obtained materials was performed by powder XRD, FEG-SEM, UV-Vis reflectance spectroscopy, BET surface area measurements, and TG-DTA. Several cells were assembled using N719 as dye and a nonvolatile electrolyte based on benzonitrile. The cells were tested by means of $J-V$ curves under simulated solar radiation, IPCE, and dark current measurements. The highest efficiencies were achieved with titania prepared by using Pluronic P123 as template $\left(\eta_{\max }=6.8 \%\right)$, while the lowest efficiencies were recorded with using titania samples prepared with the silica nanospheres template $\left(\eta_{\min }=5.7 \%\right)$. The different performances of the samples are examined and discussed.

\section{Introduction}

Since they appeared in 1991 [1], dye-sensitized solar cells (DSSCs) have been attracting the attention of the scientific community worldwide because of their peculiarities in comparison with other photovoltaic devices, that is,

(i) simple design;

(ii) ease of fabrication;

(iii) low cost;

(iv) no need of the extremely expensive equipment such as that necessary for conventional photovoltaics.

In spite of these advantages, 23 years passed without a commercial large scale implementation of DSSCs and this was mostly due to two most important drawbacks, that is, relatively low efficiency (about 12\% for the highest performance, lab scale devices [2]) and limited lifespan, especially in the case of high performance prototypes using acetonitrile as electrolyte solvent [3].
Notwithstanding their weak points, DSSCs remain attractive because of their design, open to several improvements in each one of the main parts, that is, wide band gap semiconductor, sensitizer, electrolyte, and counter electrode. In this light, our recent work was addressed

(i) to modify the photoanode to improve electron diffusion through it by inserting multiwalled carbon nanotube in the anatase nanoparticles building in this way conductor-semiconductor Schottky junctions [4];

(ii) to improve the electronic properties of anatase by controlled doping with $\mathrm{Sc}^{3+}$ ions [5];

(iii) to develop new and high performance electrolytic compositions based on benzonitrile as solvent, being characterized by low volatility and high stability [6].

If we now focus our attention on the semiconductor improvement, it is evident that its properties can be tailored not 
only by modifying it chemically or physically but also by optimizing its morphology.

In a DSSC, the morphology of the semiconductor is of key importance for determining its efficiency. In effect, dyesensitized semiconductors shifted from a mere laboratory curiosity to a promising level when dye-sensitized titanium dioxide was used as a nanocrystalline powder instead of a bulk form [1]. Nanocrystalline titania permitted a marked increase of the operation performances because of its quite high specific surface area which in turn allowed a high concentration of dye molecules per unit of surface area of the final device. Besides, by adding an opaque "scattering layer" [7] to the transparent nanocrystalline $\mathrm{TiO}_{2}$ layer, the operation of DSSCs has been enhanced. Submicrometric $\mathrm{TiO}_{2}$ particles are employed as scattering layer to retrieve the light not absorbed during the first passage through the nanocrystalline film. Mesoporous structures are proven to be effective in combining the high specific surface area of transparent nanocrystalline titania with the light scattering properties of opaque (submicrometric titania) [8]. Because of its importance in the fields of catalysis and energy conversion and storage, many synthetic approaches to mesoporous titania have been reported in literature; recently a complete review on these materials was published [9]. Scope of the present paper is to show and discuss the results we obtained by using some of the most promising mesoporous titanias which were synthesized and characterized to be the active material of the photoanodes of dye-sensitized solar cells.

\section{Experimental}

2.1. Materials. Titanium (IV) isopropoxide (TIP) (Vertec, 97 $+\%$ ), titanium (IV) fluoride (98\%), lithium iodide (ultradry, 99.999\%), and tetrafluoroboric acid (48\% in water) were purchased from Alfa Aesar. Titanium (IV) chloride (99.9\%), titanium (IV) propoxide (98\%), iodine (99.999\%), 4-tertbutylpyridine (TBP) (96\%), acetonitrile (absolute, $\geq 99.5 \%$, over molecular sieves), ditetrabutylammonium cis-bis(isothiocyanato)bis(2,2' -bipyridyl-4,4' -dicarboxylato)ruthenium (II) (N719 dye, 95\%), tetrabutylammonium hydroxide 30 -hydrate, ethanol (absolute, $\geq 99.8 \%$ ), hydrogen peroxide solution (34.5-36.5\%), acetic acid (99-100\%), ammonium hydroxide solution $(30-33 \%)$, hydrochloric acid $(\geq 37 \%)$, anhydrous terpineol, 5-15 mPa.s ethyl cellulose (48.0$49.5 \% \mathrm{w} / \mathrm{w}$ ethoxyl basis), $30-70 \mathrm{mPa} \cdot \mathrm{s}$ ethyl cellulose (48.0-49.5\% w/w ethoxyl basis), 1-hexadecylamine (HDA) (technical, 90\%), tetraethyl orthosilicate ( $\geq 99.0 \%)$, Pluronic P123, Brij 58, guanidinium thiocyanate (GuSCN) ( $\geq 99 \%)$, and benzonitrile $(99.9 \%)$ were purchased from Sigma Aldrich. Hydrogen hexachloroplatinate (IV) hydrate (40\% Pt by weight) was purchased from Chempur. 1-Ethyl-3-methylimidazolium iodide (EMII) (>98\%) was purchased from Iolitec (Germany). All the chemicals were used as received with the exception of 4-tert-butylpyridine, which was vacuum distilled before use, and benzonitrile, which was used after prolonged drying ( $>72 \mathrm{~h}$ ) over activated $3 \AA$ molecular sieves.

$3 \mathrm{~mm}$ thick FTO glass slides with sheet resistances of $10 \Omega / \square$ and $15 \Omega / \square$ for the photoanode and cathode, respectively, were purchased from XOP Fisica (Spain).
Aeroxide VP P90 fumed titanium dioxide was kindly given as a free sample by Evonik.

Surlyn (Dupont) hot melt thermoplastic was used to seal the cells ( $25 \mu \mathrm{m}$ thick) and the holes for the insertion of the electrolyte (60 $\mu \mathrm{m}$ thick); in this last case it was covered with a thin microscope glass slide.

Cerasolzer CS246-150 soldering alloy was purchased from MBR Electronics (Switzerland).

Kynar PVDF 502-CUH-HC film was used as antireflection and UV blocking layer $(<400 \mathrm{~nm})$ and was kindly given as free sample by Arkema Inc.

2.2. Syntheses of Mesoporous Titanias. Three different synthetic approaches were adopted [10-12]. $\mathrm{SiO}_{2}$ nanoparticles (hard template) were used to produce mesoporous single crystals according to [10]. The template preparation procedure resulted in two groups of $\mathrm{SiO}_{2}$ nanoparticles having mean size of 50 and $20 \mathrm{~nm}$ that were seeded in $10^{-5}$ and $10^{-4} \mathrm{M}$ aqueous solution of $\mathrm{TiCl}_{4}$, respectively. The samples were labelled as MSC-1 and MSC-2, respectively. In the case of the synthesis described in [11] (soft template), two samples were produced, differing for the gelation procedure only. In one case (sample labelled as P123-A), the sol was transferred into a crystallizing dish and kept at $40^{\circ} \mathrm{C}$ in an oven for $24 \mathrm{~h}$. In the other case (sample labelled as P123-B), the sol was left in the uncapped reaction flask and kept at $40^{\circ} \mathrm{C}$ for 1 week by means of an oil bath. Only one sample was prepared following the procedure presented in [12] and called $\mathrm{TiO}_{2}$ - $\mathrm{Brij}$ (also soft template).

2.3. Materials Characterization. Powder X-ray diffraction analysis of the produced solids was performed by using a Panalytical X'Pert PRO MPD diffractometer employing a $\mathrm{Cu} \mathrm{K} \alpha$ source $(\lambda=0.154184 \mathrm{~nm})$ and a X'Celerator ultrafast RTMS detector. The angular resolution (in $2 \theta$ ) was $0.001^{\circ}$. A $0.04 \mathrm{rad}$ soller slit, a $1^{\circ}$ divergence slit, and a $20 \mathrm{~mm}$ mask were used on the incident beam path, while a $6.6 \mathrm{~mm}$ antiscatter slit and a 0.04 rad collimator were used on the diffracted beam path.

By using the MAUD software package [13], the Rietveld analysis of the obtained patterns was performed.

Low angle scans $\left(0.5-10^{\circ}\right)$ were performed on P123-A, P123-B, and $\mathrm{TiO}_{2}-$ Brij samples by using a beam knife, $20 \mathrm{~mm}$ mask, a $1 / 8^{\circ}$ divergent slit, and a $5 \mathrm{~mm}$ antiscatter slit. The soller slit and the collimator were the same as above.

Scanning electron microscope images of the samples were obtained by using a Zeiss Auriga FESEM microscope.

The surface area of powder samples was determined by using a Quantachrome Monosorb single point BET system.

The band gap of the materials was calculated using the UV-Vis reflectance spectra of the samples. The spectra were collected in the range $220-800 \mathrm{~nm}(5.64-1.55 \mathrm{eV})$, using a double-beam spectrophotometer (Shimadzu, Japan, model UV2600) equipped with a diffuse reflectance integrating sphere accessory. Baseline spectra were collected using pressed $\mathrm{BaSO}_{4}$ powder compacts that were placed in the sample and reference beams. Data were collected at a scan rate set in slow mode and a slit width of $0.5 \mathrm{~nm}$. Band gap values 
were extrapolated from the Tauc plots of the Kubelka-Munk function calculated for the indirect interband transition [14].

Simultaneous TG-DTA analyses were performed on the samples prepared by making use of organic templating agents (P123-A, P123-B, and $\mathrm{TiO}_{2}$-Brij) before calcination. The measurements were performed in an $\mathrm{Ar} / \mathrm{O}_{2}$ mixture $(80 / 20 \mathrm{vol} / \mathrm{vol})$ in the range $\mathrm{RT}-800^{\circ} \mathrm{C}$ with a scan rate of $5^{\circ} \mathrm{C} / \mathrm{min}$.

2.4. Device Fabrication. Dye-sensitized solar cells were prepared according to the procedure reported in [5], including the sensitization process. $\mathrm{TiO}_{2}$ screen printing pastes were prepared from the obtained titania samples according to literature $[15,16]$. On account of MSC-1 and MSC-2 small specific surface area, an equal part of Aeroxide VP P90 fumed titanium dioxide was added for the preparation of the pastes in order to promote sintering of the films. The pastes were screen-printed onto $10 \Omega / \square$ FTO glass slides and the screenprinting process was repeated up to reaching a thickness between 12 and $15 \mu \mathrm{m}$ (after sintering). The thickness of the photoanodes was measured by using a stylus profilometer (model MAP3D-25, A.P.E. Research, Italy) with a nominal resolution of $10 \mathrm{~nm}$.

The electrolytic composition used was $0.6 \mathrm{M}$ EMII, $0.5 \mathrm{M}$ TBP, 0.1 M GuSCN, 0.1 M LiI, and $0.03 \mathrm{M} \mathrm{I}_{2}$ in benzonitrile [6].

Using a MBR Electronics USS-9210 Ultrasonic Soldering System with the Cerasolzer CS246-150 as soldering alloy, the contacts to the cells were soldered.

2.5. Device Testing. The 1286 Electrochemical Interface from Solartron Analytical, UK, using the Full Combo ZPLOT/ CorrWare software by Scribner Associates Inc., USA, was used to collect the $J-V$ curves. The $J-V$ curves were acquired in potential stair-step mode with a step size of $10 \mathrm{mV}$ and a step time of $1 \mathrm{~s}$. Data acquisition was repeated until a reproducible behavior was observed. An Asahi Spectra HAL-320, AM $1.5 \mathrm{G}$ class A solar simulator was used for determining the conversion efficiency. Before the tests, a calibrated Asahi Spectra Sun Checker was used to check the intensity of the radiation to be within $\pm 1 \%$ of 1 sun.

Dark current curves were collected with the same settings of those collected under illumination.

The incident photon to current conversion efficiency (IPCE) was measured in DC mode with a white light bias by a custom-made apparatus [5]. All the measurements were performed in the wavelength range $400-800 \mathrm{~nm}$ with a scan interval of $5 \mathrm{~nm}$.

\section{Results and Discussion}

3.1. Materials Characterization. The diffraction patterns of all the samples after calcination are shown in Figure 1(a), while the results of the Rietveld refinement procedure are summarized in Table 1. All the materials are monophasic, displaying only anatase diffraction lines. For comparison purposes, reference lines are displayed in Figure 1(b) [17]. MSC-1 and MSC-2 show the highest crystallite size (66 and $90 \mathrm{~nm}$, resp.) while the lowest crystallite size was shown by
TABLE 1: Rietveld refinement results of the X-ray diffraction patterns of the samples under study. Unit cell axes and estimated crystallite size values are given.

\begin{tabular}{lccc}
\hline Sample & $a / \AA$ & $c / \AA$ & $D / \mathrm{nm}$ \\
\hline MSC-1 & $3.794 \pm 0.002$ & $9.502 \pm 0.008$ & $\sim 66$ \\
MSC-2 & $3.790 \pm 0.001$ & $9.505 \pm 0.002$ & $\sim 90$ \\
P123-A & $3.788 \pm 0.002$ & $9.506 \pm 0.008$ & $\sim 13$ \\
$\mathrm{P}_{2} 3-\mathrm{B}$ & $3.791 \pm 0.001$ & $9.513 \pm 0.006$ & $\sim 13$ \\
$\mathrm{TiO}_{2}$-Brij & $3.788 \pm 0.002$ & $9.51 \pm 0.01$ & $\sim 10$ \\
\hline
\end{tabular}

$\mathrm{TiO}_{2}$-Brij $(10 \mathrm{~nm})$, not significantly different from that of P123-A and P123-B samples (13 nm for both ones) though. The refined values for the $a$ and $c$ axes of the anatase unit cell show no significant differences between the various samples.

While the crystallite size of the MSC-1 and MSC-2 samples is consistent with their relatively low specific surface areas, $\mathrm{P} 123-\mathrm{A}, \mathrm{P} 123-\mathrm{B}$, and $\mathrm{TiO}_{2}-\mathrm{Brij}$ crystallite sizes seem to contradict the values of the first two which are practically 1.5 times higher than that of the latter ones (see below). This apparent discrepancy is easily solved by the SEM images, in which, as shown later, the morphology of $\mathrm{TiO}_{2}$-Brij appears clearly much more compact than in the case of P123-A and P123-B samples.

Low angle scans $\left(0.5-10^{\circ}\right.$ in $\left.2 \theta\right)$ were performed on all the samples, in order to verify the presence of an ordered array of mesopores. Only in one case (P123-A before calcination, green curve in Figure 2), two large peaks were detected, centered at $0.711^{\circ}$ and $4.353^{\circ}$ degrees, corresponding to two distributions of mesopores centered at $\sim 124 \AA$ and $\sim 20 \AA$, respectively. In the inset of the figure, a magnification of the peak centered at $0.711^{\circ}$ is shown. The peaks disappear after calcination (red curve in Figure 2) probably due to the thermal induced crystallization of the sample.

SEM micrographs for samples MSC-1, MSC-2, P123-A, P123-B, and $\mathrm{TiO}_{2}-$ Brij are shown in Figures 3, 4, 6, 7, and 8, respectively. For both MSC-1 and MSC-2, well-formed, highly anisotropic crystals are evident, with a pore pattern that is an exact negative replica of the $\mathrm{SiO}_{2}$ template (in Figure 5, a micrograph of the template used for MSC-1 is displayed). The samples $\mathrm{P} 123-\mathrm{A}, \mathrm{P} 123-\mathrm{B}$, and $\mathrm{TiO}_{2}-\mathrm{Brij}$ all show a nanocrystalline texture, with particle size values agreeing with those estimated by XRD, but $\mathrm{TiO}_{2}$-Brij shows that a much more compact morphology is with less space between the particles. The morphology of the $\mathrm{TiO}_{2}$-Brij sample may justify the value of its specific surface area that is lower than for samples P123-A and P123-B.

The specific surface area values are summarized in Table 2 . There is a wide range of variation (nearly one order of magnitude) between the various samples. The values span from $13 \mathrm{~m}^{2} \mathrm{~g}^{-1}$ for MSC-1 to $120 \mathrm{~m}^{2} \mathrm{~g}^{-1}$ for both P123-A and P123-B and the $\mathrm{TiO}_{2}$-Brij sample lies halfway, with $75 \mathrm{~m}^{2} \mathrm{~g}^{-1}$.

The band gap values are reported in Table 3 . These values range between $\sim 3$ and $\sim 3.2 \mathrm{eV}$ (P123-A and MSC-2, resp.). Although quantum size effects are supposed to increase the band gap as the particle size decreases, in the present case the values for the samples with lower particle sizes show smaller 


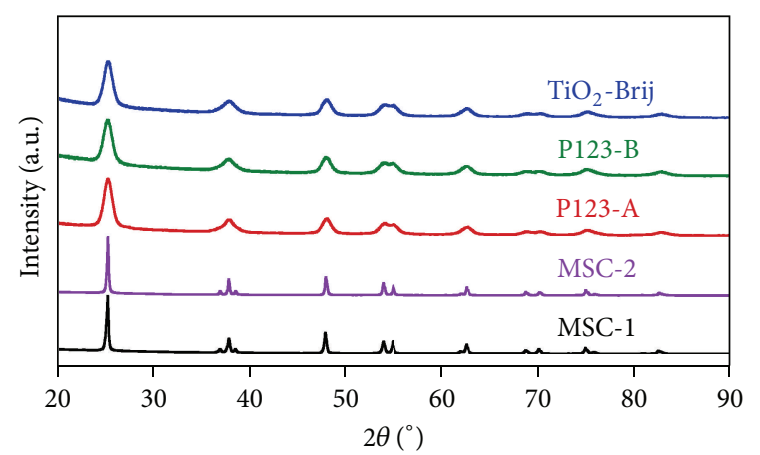

(a)

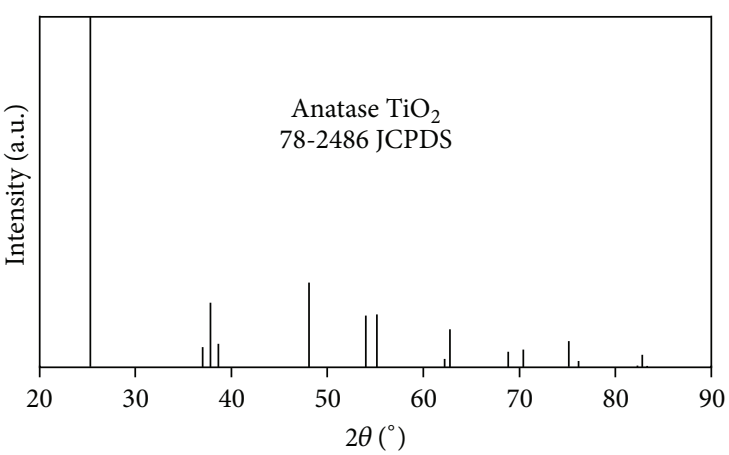

(b)

FIGURE 1: XRD patterns of the samples after calcination (a) and reference pattern (b).

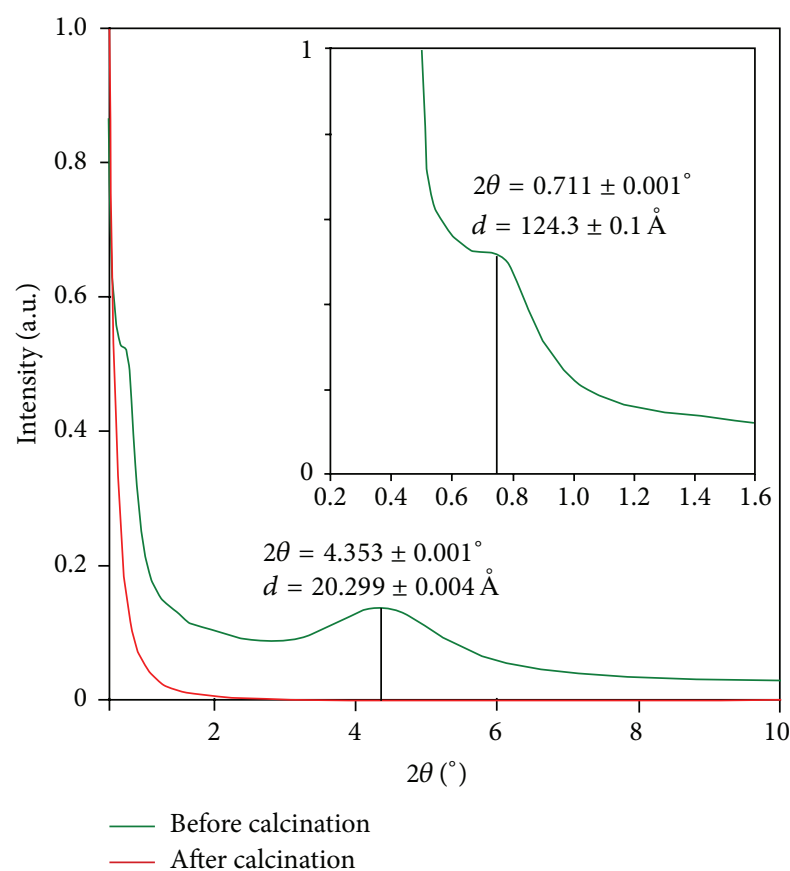

FIGURE 2: Low angle diffraction pattern of P123-A sample before calcination (green curve) and after calcination (red curve). In the inset, a magnification of the green curve in the lowest angle region (up to $1.6^{\circ}$ ) is given to better appreciate the peak centered at $0.711^{\circ}$.

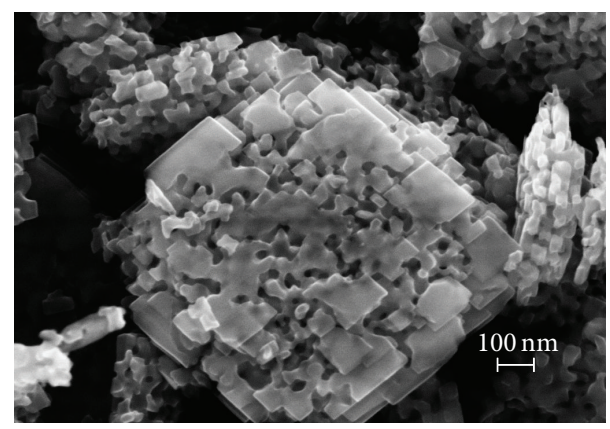

FIGURE 3: SEM micrograph of sample MSC-1. The well-defined crystal structure possesses a mesoporous pattern which is a replica of the silica template (see Figure 5).

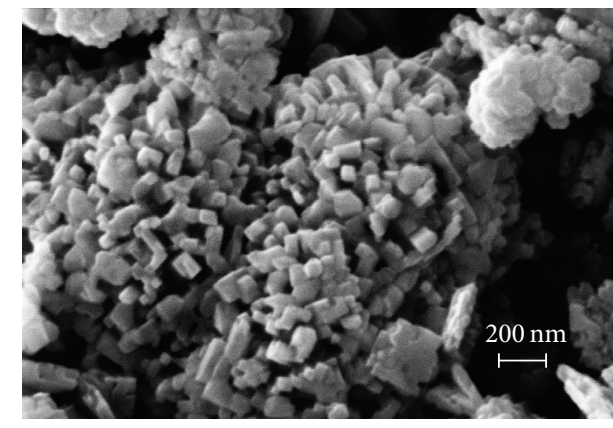

FIGURE 4: SEM micrograph of sample MSC-2.

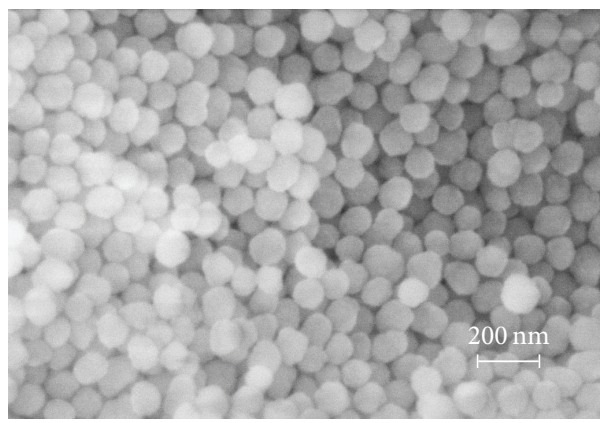

FIGURE 5: SEM micrograph of the silica template used for the synthesis of the sample MSC-1.

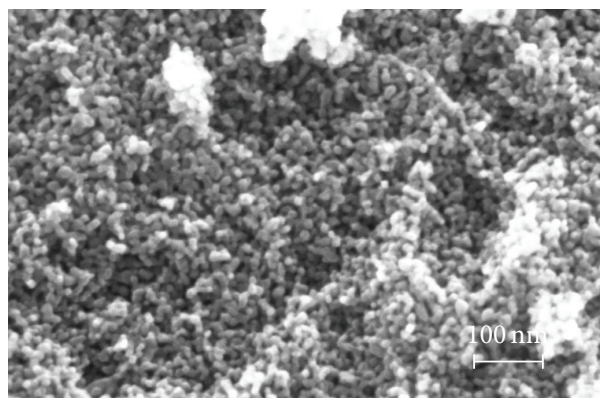

Figure 6: SEM micrograph of sample P123-A. 


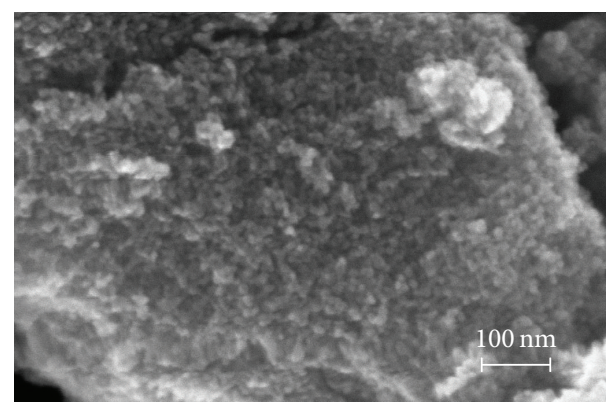

FIGURE 7: SEM micrograph of sample P123-B.

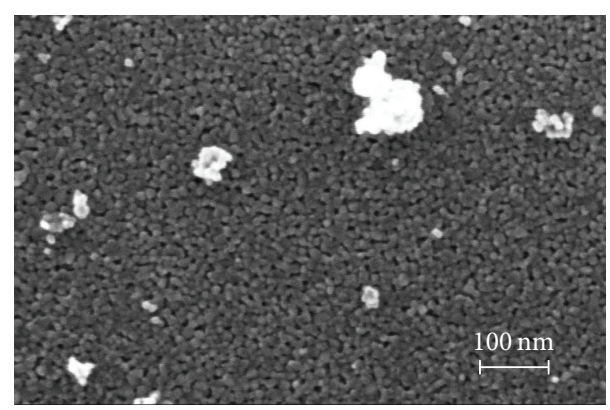

Figure 8: SEM micrograph of sample $\mathrm{TiO}_{2}$-Brij. The morphology appears clearly more compact, with less interparticle voids than for P123-A and P123-B samples.

TABLE 2: Specific surface area values of the different mesoporous titania samples.

\begin{tabular}{lc}
\hline Sample & Specific surface area $/ \mathrm{m}^{2} \mathrm{~g}^{-1}$ \\
\hline MSC-1 & $13 \pm 2$ \\
MSC-2 & $16 \pm 2$ \\
P123-A & $120 \pm 5$ \\
P123-B & $120 \pm 4$ \\
$\mathrm{TiO}_{2}$-Brij & $75 \pm 3$ \\
\hline
\end{tabular}

TABLE 3: Band gap values of the samples under study extrapolated from the Tauc plots of the Kubelka-Munk function calculated for the indirect interband transition.

\begin{tabular}{ll}
\hline Sample & Band gap/eV \\
\hline MSC-1 & $3.154 \pm 0.003$ \\
MSC-2 & $3.190 \pm 0.002$ \\
P123-A & $3.123 \pm 0.003$ \\
P123-B & $2.997 \pm 0.003$ \\
$\mathrm{TiO}_{2}$-Brij & $3.065 \pm 0.002$ \\
\hline
\end{tabular}

band gap values. This phenomenon is not surprising and reported in literature [18]. Moreover, the trend is confirmed by the $V_{\mathrm{OC}}$ values following the same trend of the band gap values [19]. The addition of Aeroxide VP P90 should not modify significantly the $V_{\mathrm{OC}}$ values of DSSC devices in the case of MSC samples, its band gap being practically identical $(\sim 3.2 \mathrm{eV})$.

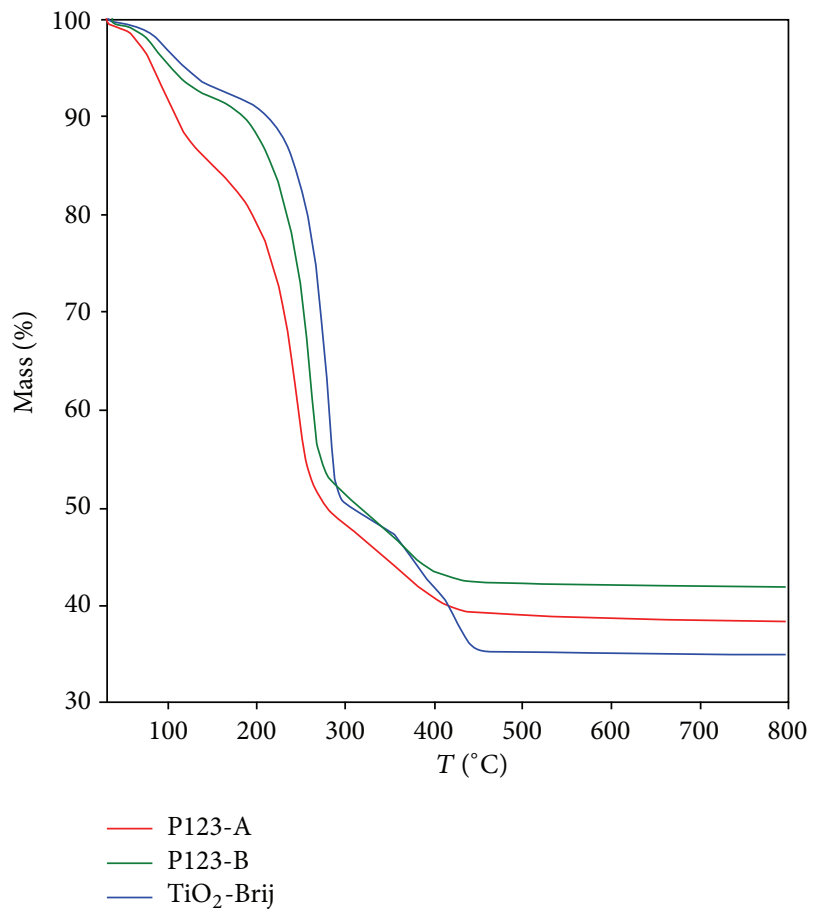

Figure 9: TGA profiles for P123-A, P123-B, and $\mathrm{TiO}_{2}$-Brij samples in an $\mathrm{Ar} / \mathrm{O}_{2}$ atmosphere $80 / 20 \mathrm{vol} / \mathrm{vol}$ analyzed before calcination.

TG and DTA curves for noncalcined P123-A, P123-B, and $\mathrm{TiO}_{2}$-Brij samples are shown in Figures 9 and 10, respectively. P123-A and P123-B samples show an almost identical behaviour, and $\mathrm{TiO}_{2}$-Brij's behaviour is also very similar to the other samples though being synthesized differently. All the samples show three distinct weight losses as well as three thermal events: the first being endothermic and the last two being exothermic. The first weight loss (RT to $150-200^{\circ} \mathrm{C}$ ) can be attributed to moisture and/or solvent loss, while the other two losses (a more pronounced one up to about $300^{\circ} \mathrm{C}$ and another up to $400-450^{\circ} \mathrm{C}$ ) can be attributed to two combustion events. After solvent evaporation, the templating agents (Pluronic P123 for samples P123-A and P123-B and Brij 58 for $\mathrm{TiO}_{2}$-Brij sample) remain the only combustible materials. Hence, the two clearly distinct combustion peaks (DTA curves in Figure 10) can belong to the templating agents burning off in two different regions of the samples: the outer surface (the most reactive, easily accessible to oxygen) and the inner pores (the least reactive and accessible to oxygen). This fact can be considered an indirect proof of the porosity of the samples analysed.

3.2. Device Testing. In Figure 11, J-V curves under illumination and in the dark are displayed, while the parameters calculated from these curves are summarized in Table 4. Short circuit current density $\left(J_{\mathrm{SC}}\right)$, open circuit voltage $\left(V_{\mathrm{OC}}\right)$, conversion efficiency $(\eta)$, fill factor $(\mathrm{FF})$, and series resistance $\left(R_{S}\right)$ are all calculated from the $J-V$ curves under illumination; $R_{S}$ was calculated from the values of the derivatives of the $I-V$ curves at $V_{\mathrm{OC}}$ assuming the cells behave like diodes. 
TABLE 4: DSSC parameters extrapolated from $J-V$ curves under irradiation and in the dark. $J_{\mathrm{SC}}, V_{\mathrm{OC}}, \eta, F F$, and $R_{S}$ were obtained from curves under illumination, while $J_{0}$ and $m$ were obtained from the high voltage part of the curves in dark using modified diode equation (3).

\begin{tabular}{|c|c|c|c|c|c|c|c|}
\hline Sample & $J_{\mathrm{SC}} / \mathrm{mA} \mathrm{cm}^{-2}$ & $V_{\mathrm{OC}} / \mathrm{V}$ & $\eta / \%$ & $F F$ & $R_{S} / \Omega$ & $J_{0} / \mathrm{nA} \mathrm{cm}^{-2}$ & $m$ \\
\hline MSC-1 & $12.5 \pm 0.1$ & $0.7311 \pm 0.0001$ & $6.0 \pm 0.1$ & $0.65 \pm 0.01$ & $104 \pm 3$ & $108 \pm 3$ & $2.41 \pm 0.01$ \\
\hline MSC-2 & $10.9 \pm 0.1$ & $0.7422 \pm 0.0001$ & $5.7 \pm 0.1$ & $0.70 \pm 0.01$ & $94 \pm 3$ & $90 \pm 4$ & $2.78 \pm 0.01$ \\
\hline P123-A & $13.4 \pm 0.1$ & $0.7122 \pm 0.0001$ & $6.7 \pm 0.1$ & $0.70 \pm 0.01$ & $84 \pm 2$ & $1.7 \pm 0.1$ & $1.76 \pm 0.01$ \\
\hline P123-B & $14.5 \pm 0.1$ & $0.7088 \pm 0.0001$ & $6.8 \pm 0.1$ & $0.66 \pm 0.01$ & $86 \pm 1$ & $0.61 \pm 0.04$ & $1.59 \pm 0.01$ \\
\hline $\mathrm{TiO}_{2}$-Brij & $13.5 \pm 0.1$ & $0.7122 \pm 0.0001$ & $6.4 \pm 0.1$ & $0.66 \pm 0.01$ & $76 \pm 2$ & $1.3 \pm 0.1$ & $1.66 \pm 0.01$ \\
\hline
\end{tabular}

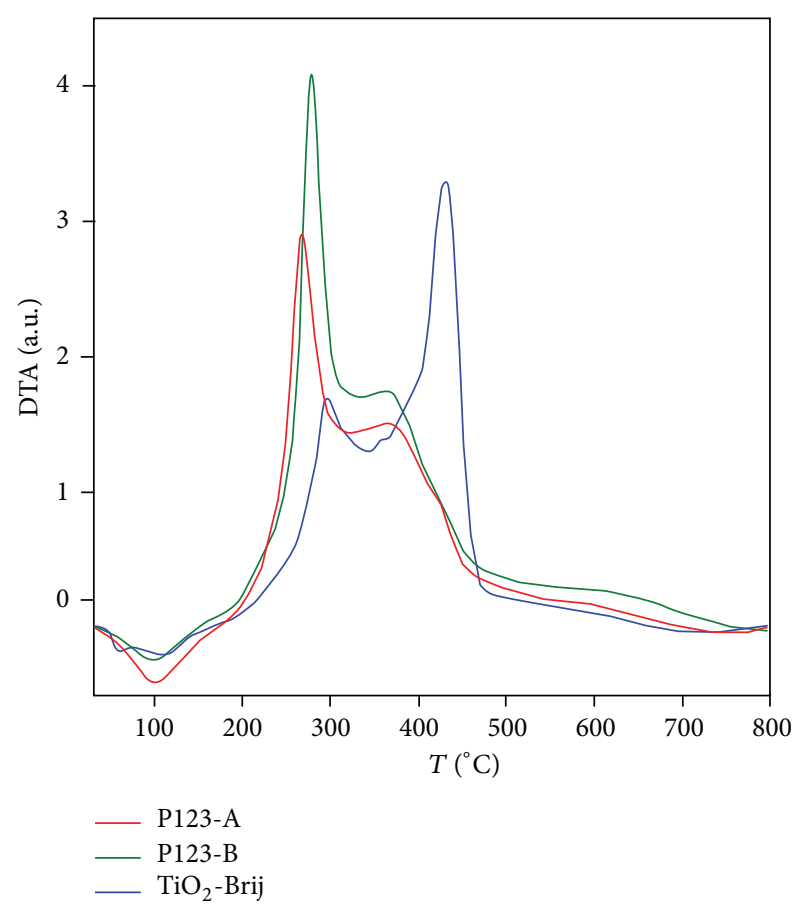

Figure 10: DTA curves for P123-A, P123-B, and $\mathrm{TiO}_{2}$-Brij samples analyzed before calcination.

The dark current curves were analysed using the modified diode equation:

$$
J_{\text {dark }}=J_{0}\left(e^{q V / m k_{B} T}-1\right),
$$

where $J_{\text {dark }}$ is the dark current density, $J_{0}$ the saturation current, $q$ the elementary charge, $m$ an ideality factor that accounts for the deviations from the behaviour of a diode, and $k_{B}$ the Boltzmann constant. At high voltages, (1) can be approximated as

$$
J_{\mathrm{dark}} \approx J_{0}\left(e^{q V / m k_{B} T}\right)
$$

and the values of the saturation current density $J_{0}$, which is directly related to the magnitude of recombination (parasitic) phenomena and of the ideality factor $m$, can be calculated by plotting $\ln J_{\text {dark }}$ versus $V$ and fitting the almost linear part at highest voltages by a straight line corresponding to the following equation:

$$
\ln J_{\mathrm{dark}} \approx \ln J_{0}+\frac{q V}{m k_{B} T},
$$

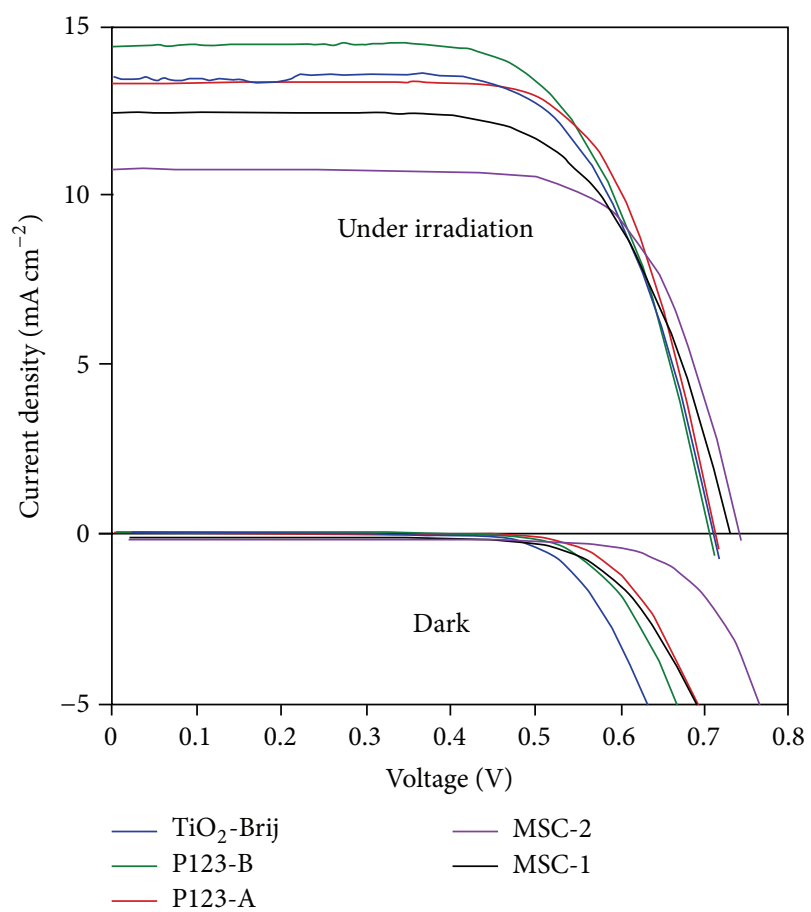

FIgURE 11: $J-V$ curves under irradiation (upper part) and in the dark (lower part) of the DSSCs assembled with the prepared titanias.

where the quantities $J_{0}$ and $m$ are obtained by intercept and slope, respectively. In Figure 12, the IPCE curves are displayed. All of them are very similar, and this is not surprising, their shape being directly related to the absorption spectrum of the dye (which is the same for all). The areas under the curves are given by

$$
J_{\mathrm{SC}}=q \int_{\lambda}\left(n_{p}\right)_{\lambda}(\mathrm{IPCE})_{\lambda} \mathrm{d} \lambda
$$

where $\left(n_{p}\right)_{\lambda}$ is the number of photons at the wavelength interval $\mathrm{d} \lambda$. Thus, the cells possessing the highest $J_{\mathrm{SC}}$ values have the highest area under curve too. Taking into account the results of all the characterizations and relating them to the device performances, the following considerations can be made.

(i) The cells using MSC-1 and MSC-2 titanias show the lowest performances of the group, and this can be justified considering that they have (a) the highest series resistance values; (b) the abnormally high $J_{0}$ 


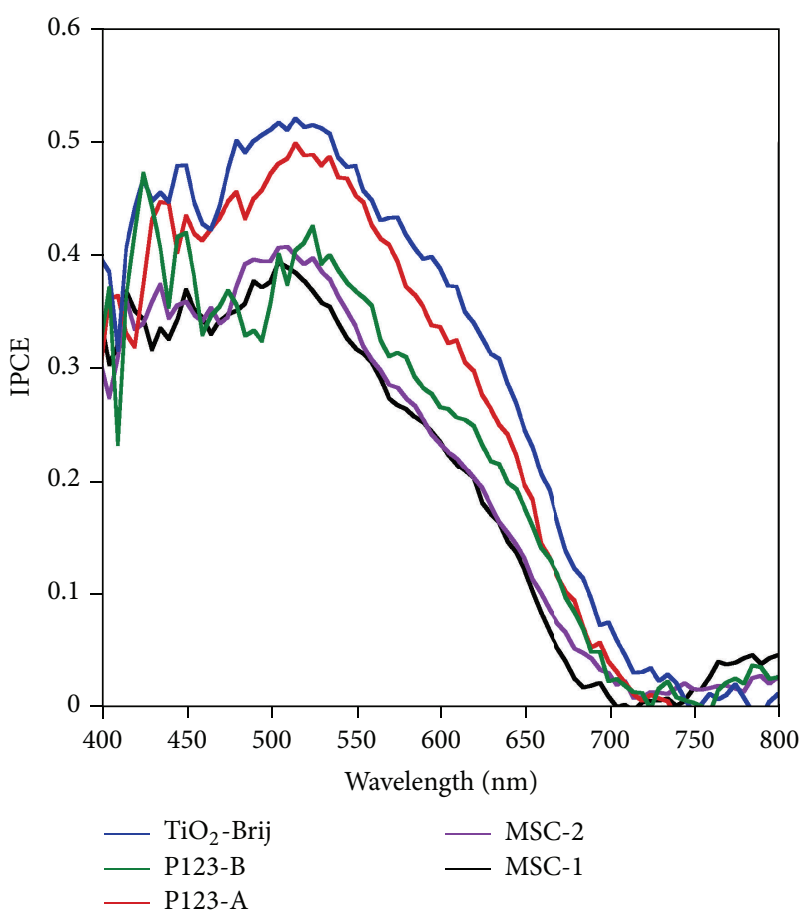

FIGURE 12: IPCE curves of the DSSC devices.

values, about 2 orders of magnitude higher than the others (this implies more recombination phenomena); (c) the highest $m$ values, so being the ones which deviate most from the ideal diode behaviour. Hence, though being much more crystalline and structurally ordered than the other titanias, MSC-1 and MSC2 are the least suitable for DSSC application. Two experimental evidences appear to be related to their lower efficiency: the lowest values of specific surface area and highest $J_{0}$ current densities. High values of the current density in dark are generally attributed to recombination processes, which can be of different nature in a DSSC other than the factors affecting $J_{0}$ as stated by the pure diode behaviour where

$$
J_{0}=a A T^{2} e^{-q \Phi_{B} / k_{B} T} .
$$

The quantity $a$ is the junction surface area (in the present case, titania particles and the conductive glass), $A$ the Richardson constant, and $\Phi_{B}$ the height of the Schottky barrier. Because there are no reliable reasons to think that the other parameters in the above equation change throughout other cells, we are confident that so low values of the specific surface area of MSC-1 and MSC-2 are responsible for a significant increase of the junction surface area between titanias and conductive glass. Though the contact among the particles is satisfactorily shown in the SEM micrographs (see Figure 3), this cannot be directly invoked to state that the junction surface area is minimized. Notwithstanding these problems, the performances of the cells are quite good, though lower than the others, and this is probably because of their high structural quality.

(ii) The cells using P123-A, P123-B, and $\mathrm{TiO}_{2}$-Brij titanias all behave in a very similar way, possessing similar efficiencies, short circuit current densities, open circuit voltages, fill factors, series resistances, saturation current densities, and ideality factors. The slight performance superiority of $\mathrm{P} 123-X$ over $\mathrm{TiO}_{2}$ Brij samples can be easily justified by their much higher specific surface area (and so dye chemisorption ability). This result is expected by considering the strict similarity between the two families of materials as it emerges from the structural (XRD, SEM) and spectroscopic analyses.

\section{Conclusions}

Mesoporous titania samples, prepared from both hard and soft template approaches, were used as dye-sensitized solar cells' photoanodes. While being structurally more perfect and so apparently more suitable for an easy electron transport through the photoanode, mesoporous titanias prepared from hard template are the least suitable for application in DSSCs because of their low specific surface area. A substantial performance improvement is expected by optimizing the dimensions of the particles that can be achieved by tailoring the synthesis conditions. On the other hand, titanias prepared from soft template approaches give a better operation and the similarity of their performances allows one to choose the synthesis on the basis of lower costs and shorter preparation times. Further improvements can be envisaged also for this class of materials, for example, by finding a way to retain the order of mesopores through thermal treatments and improving interparticle connections, which are expected to improve the dye loading and electron transport, respectively.

\section{Conflict of Interests}

The authors declare that there is no conflict of interests regarding the publication of this paper.

\section{Acknowledgments}

The authors wish to acknowledge Dr. Francesco Mura (Laboratorio di Nanotecnologie e Nanoscienze della Sapienza Università di Roma) for FEG-SEM analyses and Dr. Sergio Brutti (Dipartimento di Scienze, Università degli Studi della Basilicata) for BET specific surface area measurements.

\section{References}

[1] B. O’Regan and M. Grätzel, "A low-cost, high-efficiency solar cell based on dye-sensitized colloidal $\mathrm{TiO}_{2}$ films," Nature, vol. 353, no. 6346, pp. 737-740, 1991.

[2] A. Yella, H.-W. Lee, H. N. Tsao et al., "Porphyrin-sensitized solar cells with cobalt (II/III)-based redox electrolyte exceed 12 percent efficiency," Science, vol. 334, no. 6056, pp. 629-634, 2011. 
[3] P. Wang, Ć. Klein, R. Humphry-Baker, S. M. Zakeeruddin, and M. Grätzel, "Stable $\geq 8 \%$ efficient nanocrystalline dyesensitized solar cell based on an electrolyte of low volatility", Applied Physics Letters, vol. 86, no. 12, Article ID 123508, 3 pages, 2005.

[4] S. Quaranta, D. Gozzi, M. Tucci, L. Lazzarini, and A. Latini, "Efficiency improvement and full characterization of dyesensitized solar cells with MWCNT/anatase Schottky junctions," Journal of Power Sources, vol. 204, pp. 249-256, 2012.

[5] A. Latini, C. Cavallo, F. K. Aldibaja et al., "Efficiency improvement of DSSC photoanode by scandium doping of mesoporous titania beads," The Journal of Physical Chemistry C, vol. 117, no. 48, pp. 25276-25289, 2013.

[6] A. Latini, F. K. Aldibaja, C. Cavallo, and D. Gozzi, "Benzonitrile based electrolytes for best operation of dye sensitized solar cells," Journal of Power Sources, vol. 269, pp. 308-316, 2014.

[7] S. Ito, T. N. Murakami, P. Comte et al., "Fabrication of thin film dye sensitized solar cells with solar to electric power conversion efficiency over 10\%," Thin Solid Films, vol. 516, no. 14, pp. 46134619, 2008.

[8] F. Sauvage, D. Chen, P. Comte et al., "Dye-sensitized solar cells employing a single film of mesoporous $\mathrm{TiO}_{2}$ beads achieve power conversion efficiencies over 10\%," ACS Nano, vol. 4, no. 8, pp. 4420-4425, 2010.

[9] W. Li, Z. Wu, J. Wang, A. A. Elzatahry, and D. Zhao, "A perspective on mesoporous $\mathrm{TiO}_{2}$ materials," Chemistry of Materials, vol. 26, no. 1, pp. 287-298, 2014.

[10] E. J. W. Crossland, N. Noel, V. Sivaram, T. Leijtens, J. A. Alexander-Webber, and H. J. Snaith, "Mesoporous $\mathrm{TiO}_{2}$ single crystals delivering enhanced mobility and optoelectronic device performance," Nature, vol. 495, no. 7440, pp. 215-219, 2013.

[11] B. Tian, H. Yang, X. Liu et al., "Fast preparation of highly ordered nonsiliceous mesoporous materials via mixed inorganic precursors," Chemical Communications, no. 17, pp. 1824$1825,2002$.

[12] I. Tamiolakis, I. N. Lykakis, A. P. Katsoulidis, and G. S. Armatas, "One-pot synthesis of highly crystalline mesoporous $\mathrm{TiO}_{2}$ nanoparticle assemblies with enhanced photocatalytic activity," Chemical Communications, vol. 48, no. 53, pp. 6687-6689, 2012.

[13] L. Lutterotti, S. Matthies, and H. R. Wenk, "MAUD (Material Analysis Using Diffraction): a user friendly Java program for Rietveld texture analysis and more," in Proceedings of the 12th International Conference on Textures of Materials (ICOTOM '99), vol. 1, p. 1599, Montreal, Canada, 1999.

[14] J. Tauc, R. Grigorovici, and A. Vancu, "Optical properties and electronic structure of amorphous germanium," Physica Status Solidi B, vol. 15, no. 2, pp. 627-637, 1966.

[15] S. Ito, P. Chen, P. Comte et al., "Fabrication of screen-printing pastes from $\mathrm{TiO}_{2}$ powders for dye-sensitised solar cells," Progress in Photovoltaics, vol. 15, no. 7, pp. 603-612, 2007.

[16] A. K. Chandiran, F. Sauvage, L. Etgar, and M. Grätzel, " $\mathrm{Ga}^{3+}$ and $\mathrm{Y}^{3+}$ cationic substitution in mesoporous $\mathrm{TiO}_{2}$ photoanodes for photovoltaic applications," The Journal of Physical Chemistry C, vol. 115, no. 18, pp. 9232-9240, 2011.

[17] JCPDS-International Center for Diffraction Data, Card 782486, 2001.
[18] K. Nagaveni, M. S. Hegde, N. Ravishankar, G. N. Subbanna, and G. Madras, "Synthesis and structure of nanocrystalline $\mathrm{TiO}_{2}$ with lower band gap showing high photocatalytic activity," Langmuir, vol. 20, no. 7, pp. 2900-2907, 2004.

[19] M. Dürr, S. Rosselli, A. Yasuda, and G. Nelles, "Band-gap engineering of metal oxides for dye-sensitized solar cells," The Journal of Physical Chemistry B, vol. 110, no. 43, pp. 21899-21902, 2006. 

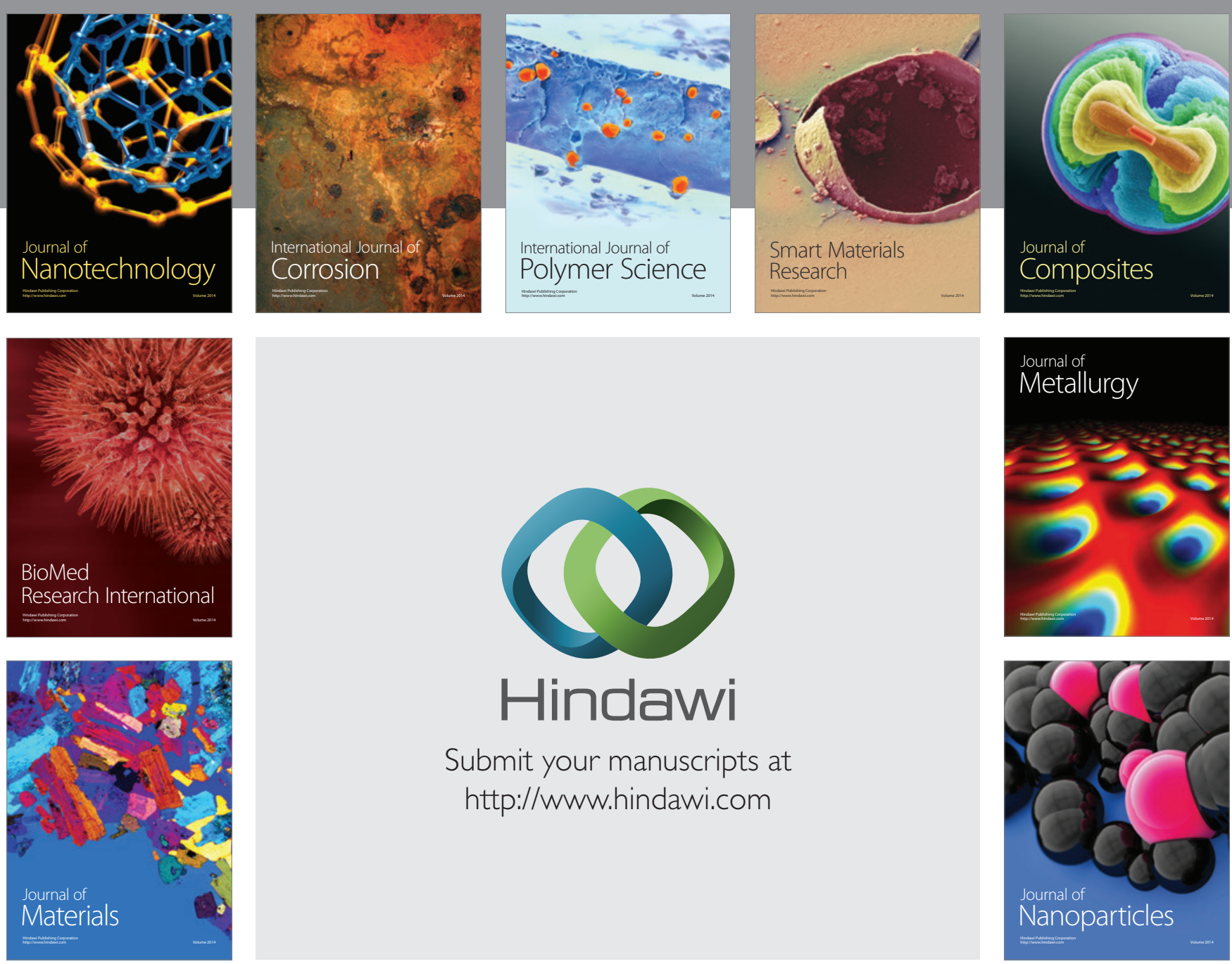

Submit your manuscripts at http://www.hindawi.com
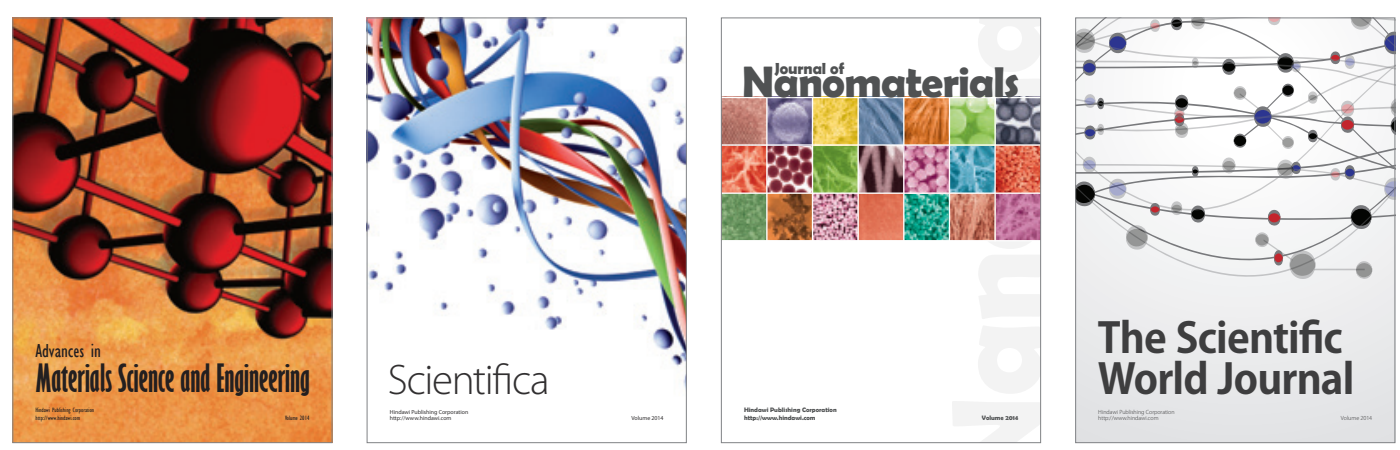

\section{The Scientific World Journal}
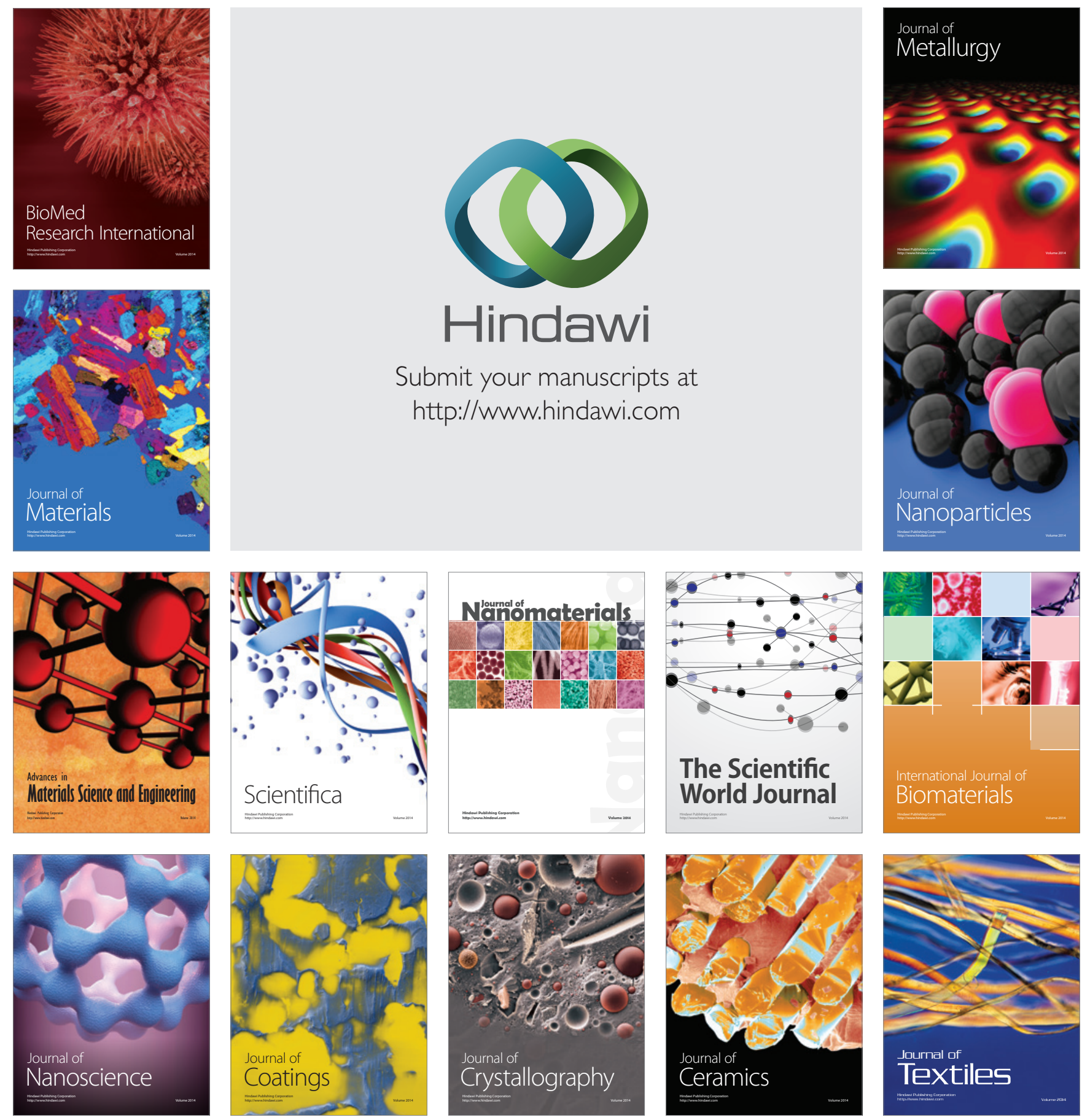